\title{
Nanomodified Composite Material Based on Aluminum
}

\author{
Kuis D. \\ Belarusian state technological University \\ Minsk, Belarus, \\ Lezhnev S. \\ Karaganda state industrial University \\ Temirtau, Kazakhstan \\ Sergey_legnev@mail.ru \\ Svidunovich N. \\ Belarusian state technological University \\ Minsk, Belarus,
}

\author{
Volochko A. \\ Physico-technical Institute of the NAS of Belarus \\ Minsk, Belarus, \\ Shegidevich A. \\ Physico-technical Institute of the NAS of Belarus \\ Minsk, Belarus,
}

Panin E.

Karaganda state industrial University

Temirtau, Kazakhstan

cooper802@mail.ru

\begin{abstract}
The aim of this work is to study the possibilities of structural-phase transformations of carbon-containing raw materials by mechanical activation and plastic deformation on dispersion strengthening and modification of aluminium composites. We studied the processes of structure formation of ligatures Al-C and Al-Si-C when they are received and thermal effects. The structural state obtained ligatures gives grounds to assert about the prospects of their use as additives providing modification and dispersion hardening when creating composite materials based on aluminum, which has a positive effect on their performance properties.

Keywords: carbonaceous raw materials, composites, ligature, aluminum.
\end{abstract}

\section{INTRODUCTION}

Due to the complex properties (low cost, low weight, high specific strength combined with ductility, corrosion resistance and others) aluminum ligatures stand out from other metal structural materials, which determines the prospects of their application in many industries while creating new devices and mechanisms, as well as the expansion of the field of use when replacing steel and expensive titanium ligatures to reduce weight and cost structures. However, at higher load-temperature conditions, these materials do not meet the requirements of the operation. Therefore, the composite materials with a higher level properties, the improvement which can be achieved through optimization of existing technologies and material compounds, as well as applying the latest technology and materials. In turn, the nanostructuring is considered as one of the most promising ways of increasing complex physico-mechanical properties of structural and functional materials. One of the most rapidly developing at present directions is the development of new nanostructured metal-matrix composite materials using nano-carbon additives.

The aim of this work is to study the possibilities of structural-phase transformations of carbon-containing raw materials by mechanical activation and plastic deformation on dispersion strengthening and modification of aluminium composites.

\section{RESEARCH METHODOLOGY}

To obtain prototypes nanomodified composite material based on aluminum was used cast deformation technology developed at GSI "Physico-technical Institute of the NAS of Belarus" [1], which includes mixing the powder components of the charge and conduct of the mechanical activation of the mixture, extruding the mixture to obtain ligatures and production of composite materials based on aluminum matrix during casting.

Samples of the ligatures were prepared from aluminum powders with a particle size of the main fraction is $5-100 \mu \mathrm{m}$ or crushed chips ligature AK9c and number of nanocarbon materials in the ratio of $\mathrm{Al}-10$ mass. $\% \mathrm{C}$ in the original mixture.

As carbon nanomaterials were used fullerene soot, fullerene $\mathrm{C}_{60}$, fullerene ligature production of Physicotechnical Institute. A.F. Ioffe, Russian Academy of Sciences, St. Petersburg.

To obtain the proposed nanomodified composite material as the base was adopted ligature AK9c. The ligature was introduced at the heating temperature of the melt $750-780^{\circ} \mathrm{C}$, while the melting ligature was $3-5 \mathrm{~min}$. Number entered in the molten composite material constituted one-tenth of the total composition. The temperature was controlled by a multichannel detector PMT-39D is connected to the PC.

Billets ( $\varnothing 40 \mathrm{~mm}, \mathrm{~h}=180 \mathrm{~mm}$ ) for the study were received in a metal mold at a cooling rate of $40-50{ }^{\circ} \mathrm{C} / \mathrm{sec}$. From the received workpieces produced samples for testing the hardness, strength, friction, wear and elongation.

Antifriction properties explored by car friction UMT 2 in the cyclic mode of lubrication (oil MG-10T): 1 drop in 10 seconds, face friction. As counterbody used steel 40X. The temperature in the friction zone does not exceed 220$250{ }^{\circ} \mathrm{C}$. Load-bearing capacity of a friction pair was 450 $480 \mathrm{MPa} \cdot \mathrm{m} / \mathrm{s}$. 
The morphology and microstructure of the samples were examined by the method of metallographic analysis with complex Micro-200. Phase composition was determined by x-ray diffractometer D8 Advance "Bruker", using the software "X-RAY" automation of x-ray phase analysis. Raman scattering were obtained, equipped with a microscope spectrometer Raman scattering RAMANOR U-1000, firms Jobyn Yvon Instruments S. A., Inc., with the wavelength of laser excitation $514 \mathrm{~nm}$, spectral resolution $1 \mathrm{~cm}^{-1}$, the spatial resolution of $2 \mu \mathrm{m}$. Fine structure and microchemical composition of the samples was investigated using a scanning electron microscope JSM-5610 LV c system qualitative and quantitative EDX microprobe analysis (Jeol, (elemental analysis was performed at the point on the square in graphical form and in the form of "X-Map" images) and transmission (transmission) electron microscope (JEOL JEM 2100, at an accelerating voltage of $200 \mathrm{kV}$.

The Brinell hardness of samples was determined on the hardness tester TS-2M at a load of $250 \mathrm{~kg}$, the ball diameter $5.0 \mathrm{~mm}$, microhardness was measured on the microhardness tester Duramin Struers with loads of 10$2000 \mathrm{~g}$.

The elongation and the strength were measured on a machine for testing the tensile-compression ZD-10/90 with a force of $10 \mathrm{kN}$.

\section{RESEARCH RESULTS AND DISCUSSION}

The results of comprehensive studies of the powder of the fullerene soot showed that the powder consists of dispersed soot particles and large particles of fullerenes. However, soot basically consists of amorphous carbon, contains the $8 \%$ of fullerenes and does not contain but a small amount of oxygen, no impurities. Carbon black is made from $100 \%$ carbon carbon, or any other impurities not detected. The powder consists of particles of small size from 3-5 microns and very large particles, but it only conglomerates. According to [2] fullerene niello is a black fine powder with a particle size of 40-50 nm.

Studies of the charge after mechanical activation showed that in the charge system Al-C and Al-Si-C at its

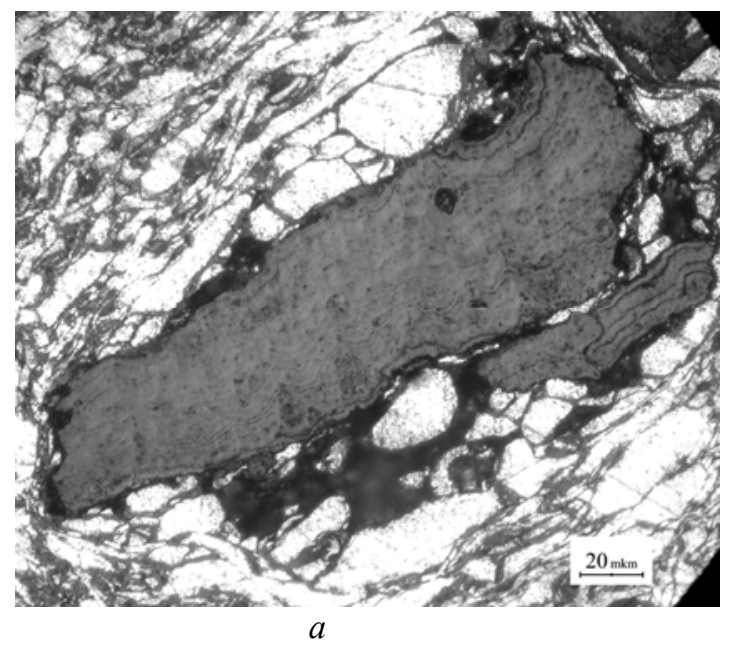

mechanical activation processes of plastic deformation of the original powder components and is not observed changes in the elemental and phase compositions. Thus obtained topogram powder mixture with different carbon additives similar.

The results of studies of the compositions of the Al-C and $\mathrm{Al}-\mathrm{Si}-\mathrm{C}$ after extrusion of the mixture showed that samples revealed unusual for aluminum ligatures superhard particles of gray (fig. 1). Micro-X-ray spectral analysis EDX established that the superhard particles of gray represent the carbon phase.

This phase contains all made with nano-carbon additives ligatures and fullerene soot and fullerene ligature, and $\mathrm{C}_{60}$. The analysis showed that the size, shape and number of extra hard pure carbon phases with high elasticity different ligatures of different compositions. The investigations did not reveal fundamental differences in the formation of ligatures $\mathrm{Al}-\mathrm{C}$ and $\mathrm{Al}-\mathrm{Si}-\mathrm{C}$, obtained with the use of expensive fullerenes, in comparison with the ligatures obtained using cheaper nano-carbon materials, which makes them promising for industrial development.

Using Raman spectroscopy light scattering we found that the obtained superhard particles of gray are amorphous material similar to glassy carbon (fig. 2). Its hardness is isotropic - that is equally high in all directions.

In parallel, a study was made possible carbide creation in the system aluminum matrix - carbon-containing material. In the study of the phase composition is determined that the ligatures obtained using nano-carbon materials (fullerenes, fullerene soot and ligature) is identified carbide component $\left(\mathrm{Al}_{4} \mathrm{C}_{3}\right.$ and/or $\left.\mathrm{SiC}\right)$ in an amount up to the $\approx 2-3 \%$.

To determine the effect of thermal treatment on the structural condition and properties of ligatures of the Al-C and $\mathrm{Al}-\mathrm{Si}-\mathrm{C}$ were developed temperature-time regimes and carried out the annealing of these ligatures, prepared samples and investigated their elemental and phase composition, structure, indicators of physical and mechanical properties.

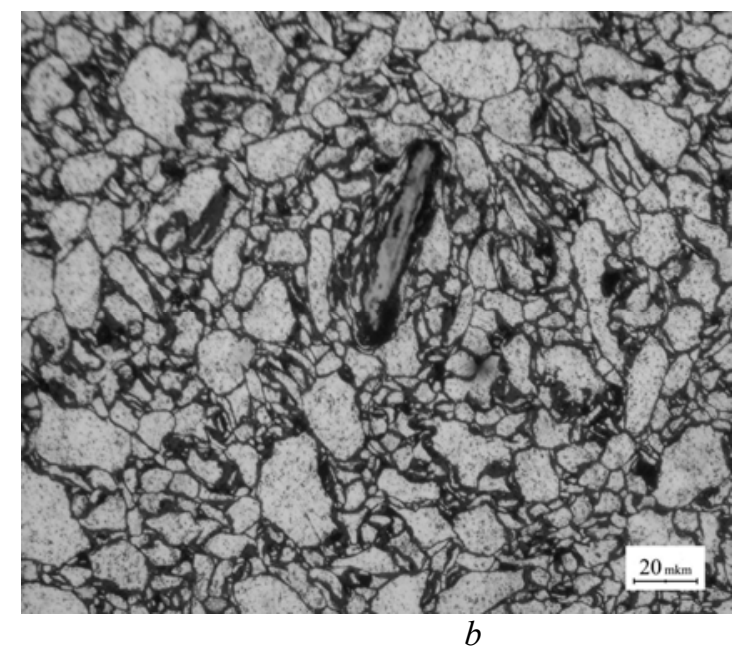




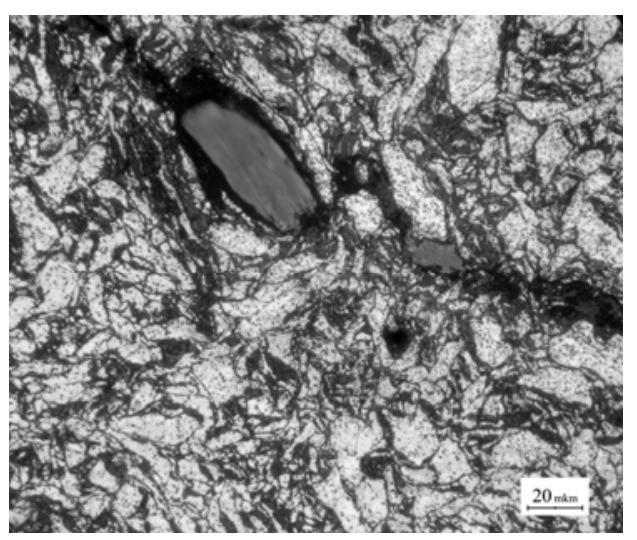

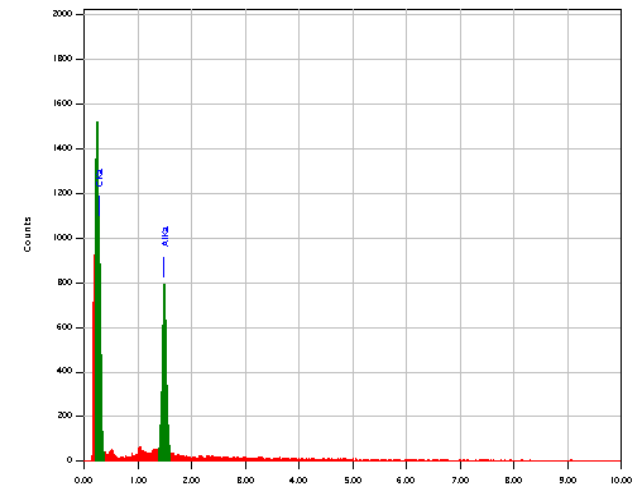

\begin{tabular}{|c|c|c|c|c|}
\hline Element & $(\mathrm{keV})$ & mass $\%$ & Error\% $\%$ & $\mathrm{At} \%$ \\
\hline $\mathrm{C} \mathrm{K}$ & 0.277 & 85.64 & 0.89 & 93.05 \\
\hline $\mathrm{Al} \mathrm{K}$ & 1.486 & 14.36 & 0.49 & 6.95 \\
\hline Total & & 100.00 & & 100.00 \\
\hline
\end{tabular}

$\mathrm{a}-\mathrm{Al}+10 \%$ fullerene niello, $\mathrm{x} 500 ; \mathrm{b}, \mathrm{c}, \mathrm{d}-$ results of microprobe analysis EDX grey phase in ligatures $\mathrm{Al}+10 \%$ fullerene niello.

Fig. 1 - Structure of the samples of the ligatures Al-C

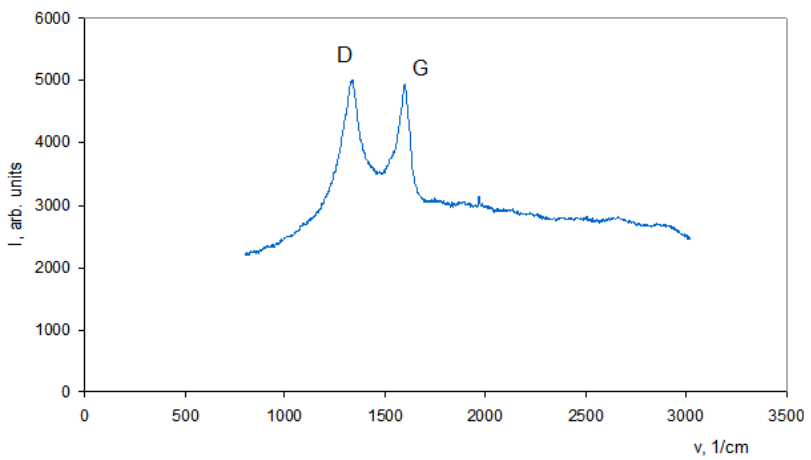

Fig. 2 - Spectrum of the Raman sample Al-10\%C

The annealing of the ligatures was carried out in a muffle furnace in air atmosphere at a temperature of $550^{\circ} \mathrm{C}$ for 1,3 and 8 hours. Determined that with increasing time of annealing of the ligatures lose their strength properties, in some cases collapse, possibly due to oxidation. However, in this study the structural state of these ligatures showed no significant changes (for longer annealing in the structure of ligatures $\mathrm{Al}-\mathrm{C}$ and $\mathrm{Al}-\mathrm{Si}-\mathrm{C}$ appears dark rimmed with aluminum grains). It should be noted that all samples ligatures with nano-carbon materials (fullerenes, fullerene soot, fullerene ligature) after annealing of different duration are stored inclusion in the gray phase, indicating its relatively high thermal stability. The thermal stability is further proof that received superhard particles of gray are amorphous material such as glass carbon. In the study of the phase composition of annealed for different time ligatures obtained almost identical to x-rays. Fig. 3 shows the structure of the ligatures $\mathrm{Al}+10 \%$ fullerene ligature after annealing at a temperature $550^{\circ} \mathrm{C}$ within 8 hours.

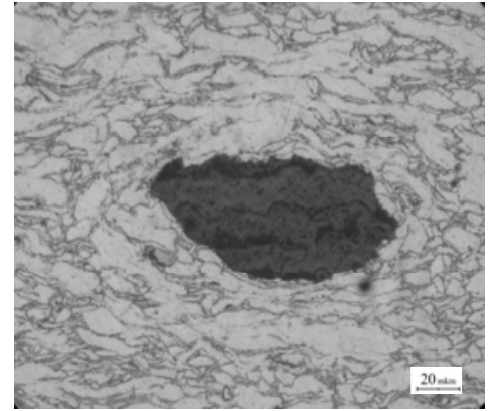

$a$

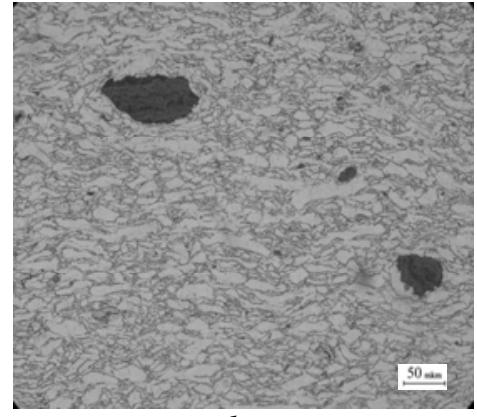

$b$

$$
a-\times 200, \mathrm{~b}-\times 500
$$

Fig. 3 - Structure of the ligature $\mathrm{Al}+10 \%$ fullerene niello after annealing

In studies of the influence of thermal effects on

structural condition and properties of ligatures Al-C was 
also conducted an experiment using ligature $\mathrm{Al}+10 \%$ fullerene niello when it is heating up to temperatures corresponding to the process of smelting ligatures based on aluminum. During this annealing samples of these ligatures were carried out in a muffle furnace in air atmosphere at a temperature of $800^{\circ} \mathrm{C}$ within 30 minutes. This ligature hold their shape and not melt. From the results of the structure of ligature samples $\mathrm{Al}+10 \%$

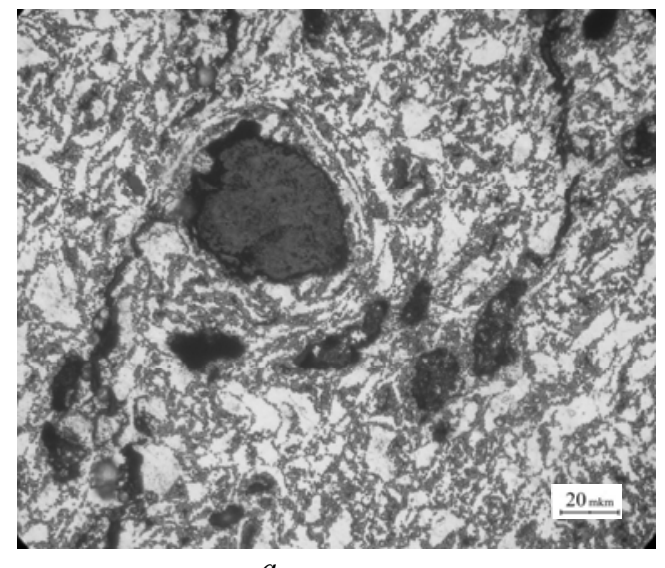

fullerene niello after annealing, is presented in fig. 4, it is seen that compared with the ligature before annealing greatly changes the morphology of the aluminum component. The microhardness of the metallic base annealed ligatures almost 2 times higher than microhardness of the metallic base ligatures before annealing. In the structure remains grey phase, which again testifies to its relatively high thermal stability. $a-\times 100, \mathrm{~b}-\times 500$

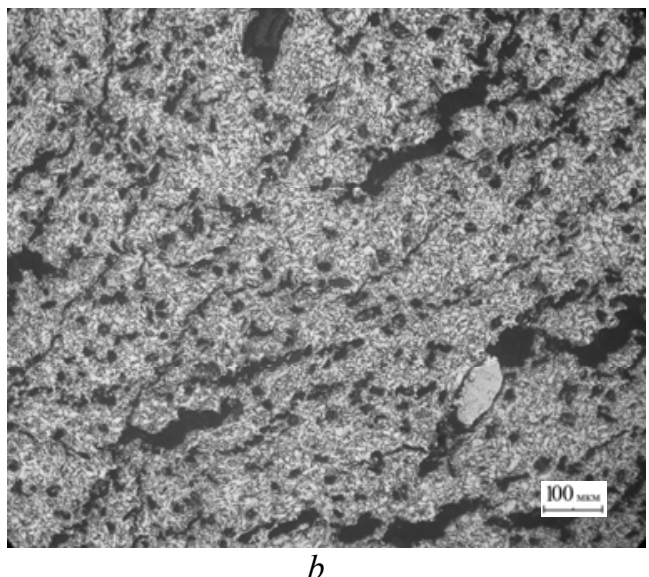

Fig. 4 - Structure of the ligature samples $\mathrm{Al}+10 \%$ fullerene niello after annealing

Studies of the phase composition annealed ligatures showed significant differences compared with the original samples, which is expressed primarily carbide creation. Carbide aluminum $\left(\mathrm{Al}_{4} \mathrm{C}_{3}\right)$ in the amount of $11-12 \%$ confidently identified, the program offers all the cards on the carbide. On the radiograph all lines of cards carbide correspond to the return line in the spectrum.

The microstructure of the aluminum alloy after treatment indicates a uniform modification of the eutectic alloy and component (fig. 5). As a result of the research it was found that the crystals of eutectic silicon diminished in 4 times, and the width of the aluminum dendrites of $\alpha$ phase decreased in 3-3,5 times.

The above results of studies of pattern formation of composites based on aluminum matrix obtained using nano-carbon materials, suggest that the amorphous-like glass carbon component patterns ligatures when introduced into the melt, contributing to the increase in the number of crystallization centers can significantly modify the structure of the alloy (figure 5) and thereby to improve the flexibility and strength of the material. Carbides of aluminum and/or silicon $\left(\mathrm{Al}_{4} \mathrm{C}_{3}\right.$ and/or $\left.\mathrm{SiC}\right)$, are also centers of nucleation in the melt processing by ligature, also provide dispersed hardening of the composite.

When testing nanomodified composite alloy with aluminum matrix showed sufficiently high mechanical and friction properties. In comparison with the source strength has increased 2.3 times and averaged $450 \mathrm{MPa}$, increased hardness almost in 2 times to NW, with plastic characteristics suggest the possibility of further plastic deformation castings $(\delta=8-10 \%)$. The presence of carbon inclusions in the microstructure contributed to the reduction of the friction coefficient is 1.9 times from 0,04 to 0.026 .

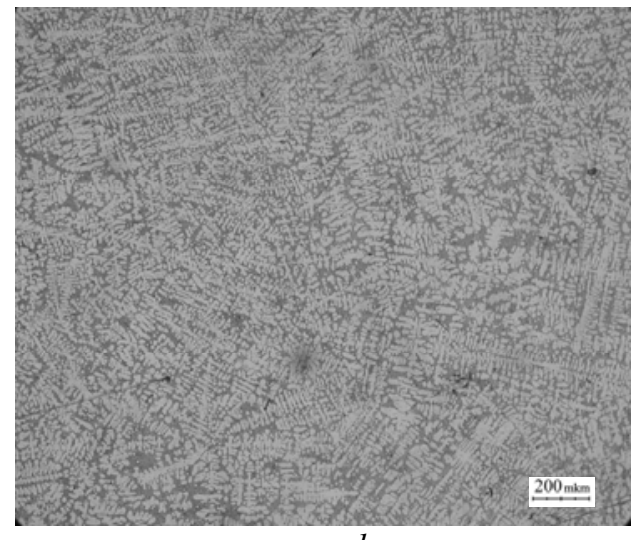

$b$ 


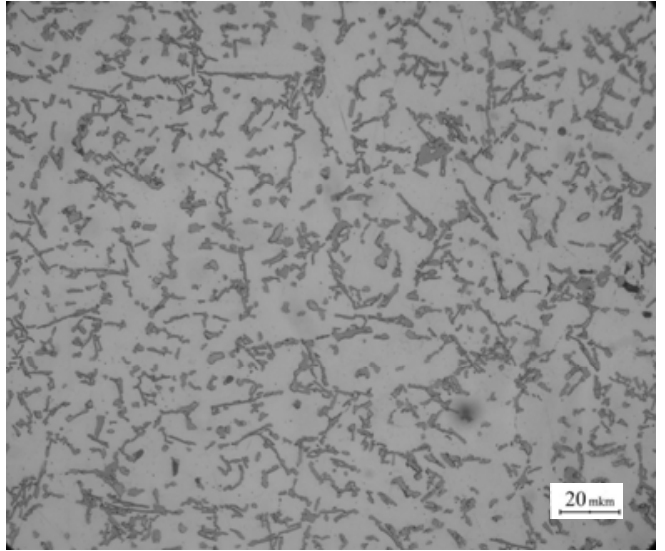

$c$

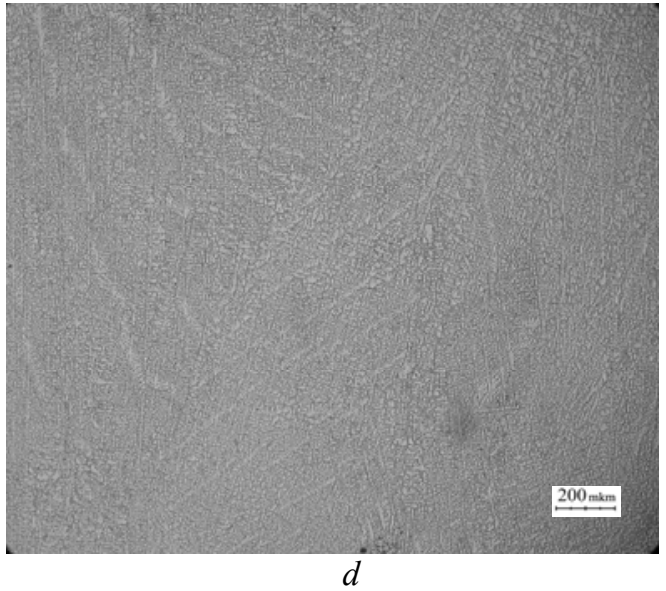

$a-\times 50,6-\times 500, c-\times 50, d-\times 500$

Fig. 5 - Microstructure of the initial alloy AK9c, composite, obtained with the use of ligatures AK9c - fullerene niello

Thus, step by step we studied the processes of structure formation of ligatures $\mathrm{Al}-\mathrm{C}$ and $\mathrm{Al}-\mathrm{Si}-\mathrm{C}$ when they are received and thermal effects. This particular interest is the formation of superhard carbon phases in the studied alloys. Study of the mechanism of structure formation of these phases is necessary for science-based management process of creating new materials. The structural state obtained ligatures gives grounds to assert about the prospects of their use as additives providing modification and dispersion hardening when creating composite materials based on aluminum, which has a positive effect on their performance properties.

\section{REFERENCES}

[1] Volochko, A.T. Processing and use of aluminum waste in the production of powders, pastes, composite and ceramic materials A.T. Volochko. - Minsk: Belarus science, 2006. - 302 p.

[2] Gusev, A.I. Nanomaterials, nanostructures, nanotechnology / A.I. Gusev. - M.: FIZMATLIT, 2009. - 416 p. 